\title{
Mulheres não podem falar de ciência? Análise de comentários sexistas em vídeo do canal Nerdologia
}

\author{
Verônica Soares da Costa \\ Doutora; Universidade Federal de Minas Gerais, Belo Horizonte, MG, Brasil; \\ ve.scosta@gmail.com \\ Carlos Alberto de Carvalho \\ Doutor; Universidade Federal de Minas Gerais, Belo Horizonte, MG, Brasil; \\ carloscarvalho0209@gmail.com
}

\begin{abstract}
Resumo: $O$ artigo debruça-se sobre o sexismo na divulgação científica a partir da análise de comentários que receberam maior número de curtidas e respostas dentre os mais de 15 mil identificados até a data da coleta - em um vídeo do canal Nerdologia sobre sexismo. O exame dos comentários indica predominância de repercussão negativa sobre a narrativa conduzida por uma mulher em ambiente originalmente comandado por apresentadores do sexo masculino. $\mathrm{O}$ objetivo do artigo é atribuir sentido às reações dos usuários como parte do ciclo comunicacional da plataforma YouTube, considerando as manifestações de curtidas e respostas como aspectos que corroboram com comentários sexistas que deslegitimam a presença feminina e distorcem argumentos de defesa da equidade de gêneros. A análise sinaliza para os modos como mulheres se encontram em posição de vulnerabilidade ao atuarem na divulgação das ciências, considerando-se os preconceitos, os estereótipos e a desqualificação como componentes de processos socioculturais, econômicos e políticos que fragilizam a atuação das mulheres em instituições que se posicionam como detentoras de privilégios - como a Ciência. Os estereótipos desqualificadores são indícios de modos de configuração do fazer e divulgar ciência, marcado por clivagens, desigualdades e hierarquizações nas relações de gênero, indicando também a necessidade de desenvolvimento de uma consciência crítica de como o gênero influencia as ciências e os processos de comunicação científica.
\end{abstract}

Palavras-chave: Sexismo. Divulgação Científica. YouTube. Comentários. Vulnerabilidade.

\section{Introdução}

Na paisagem das mídias digitais online foi criado um tipo de fórum público, em que as normas sociais entram em suspensão e a autorregulação, que tipicamente organiza as trocas estabelecidas em pessoa, passa a ser substituída por uma 
recusa do diferente. Um exemplo desse fenômeno pode ser observado no estudo de Anderson et al. (2014), no qual 1.183 participantes leram um post de notícias em um blog fictício, que explicava os potenciais riscos e benefícios de um novo produto tecnológico chamado nanosilver. $\mathrm{O}$ artigo online informava que tais partículas apresentam vários benefícios potenciais (como propriedades antibacterianas) e riscos (como a contaminação da água). Em seguida, os participantes liam comentários da postagem, supostamente de outros leitores, e respondiam a perguntas sobre o conteúdo do texto.

A simples inclusão de um ataque ad hominem em um comentário de leitor (como no exemplo Se você não vê os benefícios de usar a nanotecnologia nesses tipos de produtos, você é um idiota, grifo nosso, tradução nossa) foi suficiente para que os participantes do estudo avaliassem que a desvantagem da tecnologia relatada era maior do que tinham pensado antes de ler os comentários (ANDERSON et al., 2014, p. 378), assumindo uma postura defensiva em relação ao artigo publicado no blog. Os autores observaram que, embora seja difícil quantificar os efeitos de distorção que a leitura de comentários causa em assuntos relacionados a ciência e tecnologia, a identificação dessa diferença potencial na leitura e na apreensão de informações em contextos online é bastante substancial, particularmente na divulgação científica. $\mathrm{O}$ artigo chama esse fenômeno de nasty effect, ou efeito desagradável, em tradução livre.

Em busca de identificar as consequências desse efeito em outras circunstâncias comunicativas, este artigo propõe-se a analisar abordagens sexistas em comentários de usuários sobre temas de ciência e tecnologia, com foco específico em ações de divulgação científica, tomando como local de observação a caixa de comentários do canal Nerdologia. Reconhecido como um dos maiores canais de Ciência e Tecnologia (C\&T) no YouTube Brasil, o Nerdologia faz uso de temáticas nerd, da cultura pop e do entretenimento para tratar de assuntos diversos do universo científico. Quando da redação deste artigo, era o $77^{\circ}$ canal de $\mathrm{C} \& \mathrm{~T}$ em número de assinantes no mundo, de acordo com dados do SocialBlade (2019), e pode ser considerado um projeto pioneiro no Brasil. Em 10 de maio de 2019, contava com 452 vídeos publicados, 
ultrapassando a marca de 2 milhões e 400 mil inscritos e contabilizando mais de 223 milhões de visualizações, números relevantes para uma temática considerada de nicho.

No que tange às temáticas abordadas no canal, faz-se necessário um esforço de compreensão das dinâmicas de definição do nerd a partir de propostas como a de Kendal (1999; 2000; 2011), que discute esta cultura originada na tradição americana de produções audiovisuais e gestada em associação a um universo machista, racista, misógino e sexista. Ainda que, na concepção do canal Nerdologia, o conceito de nerd tenha sido reconfigurado e não opere em sentido pejorativo, referindo-se a um vasto universo de temas, filmes, quadrinhos, séries de TV, personagens, super-heróis, desenhos animados e outras manifestações culturais com as quais se identificam as pessoas consideradas nerds, a tradição majoritariamente masculina desse universo dá a ver conflitos nas relações entre homens e mulheres, masculino e feminino, que se manifestam nos comentários postados no canal.

A análise realizada neste estudo focou no vídeo de $\mathrm{n}^{\circ} 125$, em que o tema tratado foi o sexismo. Utilizamos um corpus composto por comentários de usuários coletados em 6 de agosto de 2017 por meio do software YouTube Data Tools (YTDT), observando inicialmente comentários que tiveram mais curtidas e mais respostas, ou seja, que geraram maior engajamento da comunidade que acompanha o canal e dos usuários que assistiram ao vídeo. Por engajamento queremos tão somente indicar respostas e repercussões específicas ao vídeo que ensejou os comentários, não interessando, nos marcos da análise, verificar se as mesmas pessoas são comentaristas regulares de outras postagens do Nerdologia. Metodologicamente, ainda é importante destacar que o objetivo não foi realizar levantamento sistemático com representatividade estatística das reações e discursos desencadeados pelo vídeo, mas discutir, a partir do que emerge na empiria, manifestações sobre sexismo, feminismo e ciência.

Uma dimensão que os comentários nos permite verificar é em que medida as mulheres, diante do universo da ciência, encontram-se em posição de vulnerabilidade (BUTLER, 2014), considerando os preconceitos, os estereótipos e a desqualificação como componentes dos processos socioculturais, 
econômicos e políticos que podem fragilizar pessoas e/ou grupos sociais diante de semelhantes e instituições que se posicionam como detentoras de privilégios. As relações entre mulheres e ciências, ou, melhor dito, a presença das mulheres como cientistas em ambientes francamente machistas e misóginos, não lhes tem permitido historicamente, em contextos sociais diversos, livrarem-se de ações que as tornam vulneráveis diante de poderes instituídos por maioria masculina, e esses efeitos se fazem presentes também nas ações de divulgação científica, conforme veremos a seguir.

\section{Ciência e sexismo: um problema de múltiplas faces}

O machismo institucional da academia e o sexismo em ambientes de produção científica e tecnológica têm sido alvo de constantes debates, principalmente em função de movimentos que lutam pelo aumento da visibilidade das mulheres nessas áreas. O escopo das manifestações públicas brasileiras em prol das mulheres na ciência vão desde premiações temáticas promovidas por instituições internacionais, como o prêmio Para Mulheres na Ciência, Programa L'OrealUnesco que, no Brasil, conta com o apoio da Academia Brasileira de Ciências $(\mathrm{ABC})$, como também projetos independentes e iniciativas institucionais, como o portal Ciência e Mulher, da Sociedade Brasileira para o Progresso da Ciência (SBPC).

Ainda que importantes do ponto de vista político-institucional, tais propostas parecem incipientes diante da continuidade de acontecimentos sexistas de grande repercussão midiática, como a declaração do bioquímico ganhador do prêmio Nobel, Tim Hunt, proferida durante a Conferência Mundial de Jornalismo Científico na Coreia do Sul, em 2015, na qual ele dizia que as cientistas devem ser segregadas de colegas do sexo masculino porque mulheres choram quando criticadas e são uma distração romântica no laboratório. A fala ganhou destaque em jornais e portais de notícia (BILEFSKY, 2015) e, logo após a declaração, Hunt renunciou ao posto de professor honorário no University College London.

O cenário de recorrentes declarações sexistas e manifestos contrários a mulheres que circulam na mídia vai de encontro a avanços como os reportados 
em relatório da editora Elsevier (2017), intitulado Gênero no panorama global da pesquisa. Divulgado no simbólico 8 de março, o documento traz um panorama sobre a produção científica de homens e mulheres em 27 áreas do conhecimento e indica que é possível falar em avanços em direção a um equilíbrio de gênero na ciência ao longo dos últimos 20 anos. O relatório aponta o Brasil como um dos países que mais avançaram nos indicadores gerais, mas esse pretenso avanço continua a não coincidir com o lugar ocupado efetivamente por mulheres na ciência, no Brasil e no mundo. Isso porque o imaginário sobre cientistas é frequentemente relacionado ao perfil do homem branco de jaleco, não a uma mulher em trajes de laboratório. Tal anedota não é aleatória, nem trivial, mas construída culturalmente e identificada por estudos realizados pelo menos desde a década de 1950, nos Estados Unidos, em que a imagem de uma ciência masculina é reforçada por um ideal de objetividade e universalidade fortemente atrelado ao imaginário masculino:

\begin{abstract}
Em 1957, na mesma época em que Barbie estava sendo projetada, a conhecida antropóloga Margaret Mead e sua colega Rhoda Métraux descobriram que o estudante secundário americano médio via o cientista como "um homem vestido num avental branco e que trabalha num laboratório. Ele é idoso ou de meia-idade e usa óculos... ele pode ter barba... ele pode estar com a barba por fazer e ser desleixado. Ele pode andar encurvado aparentando cansaço. Ele é cercado de equipamento: tubos de ensaio, inflamadores Bunsen, frascos e garrafas, um emaranhado de tubos de vidro e máquinas estranhas com mostradores'. (SCHIEBINGER, 2001, p. 146)
\end{abstract}

Mais recentemente, uma pesquisa com grupos focais de adolescentes no Rio de Janeiro (REZNIK et al., 2017) identificou “[...] uma visão positiva com relação ao avanço da inserção da mulher no mercado de trabalho e expectativa otimista das participantes sobre suas próprias carreiras profissionais." (REZNIK et al., 2017, p. 844). Mas o estudo ressalta que o interesse das jovens participantes é, principalmente, em áreas que já agregam maior contingente de mulheres, tanto no Brasil quanto em outros países, ou seja, em áreas consideradas "femininas", como cursos de ciências da saúde e ciências biológicas. Nesse contexto, a segregação vertical (OLINTO, 2011, p. 69), também chamada "teto de vidro", desempenha um papel de barreira invisível que impede mulheres de chegarem a cargos de liderança de pesquisa, por 
exemplo, um fenômeno ainda a ser superado no Brasil e no mundo. Isso porque o crescimento profissional de mulheres nas ciências pressupõe maior inserção e dedicação a atividades como atuação em programas de pós-graduação, publicação regular em periódicos de relevância internacional, aprovação de projetos e liderança de grupos de pesquisa que desencadeiam maior volume de trabalho e capacidade de diversificação da atuação profissional, fato que pode ser inviabilizador para uma parcela de mulheres acadêmicas em função de haver uma divisão do trabalho doméstico não explicitada que diz também de relações sociais de poder e dominação pautadas pelo gênero, de modo que às mulheres são atribuídas mais comumente as tarefas da vida doméstica.

Olinto (2011) destaca outros aspectos desse cenário que nos permitem compreender melhor a complexidade da situação. Ela afirma que há “[...] distribuição desproporcional entre os sexos das tarefas docentes e de orientação acadêmica na universidade, especialmente da graduação [...]" (OLINTO, 2011, p. 71), fato que diminui as chances das mulheres de se dedicarem à pesquisa e à publicação. Outra dinâmica diz respeito à "[...] necessidade que as cientistas têm de apresentar mais credenciais para obter o mesmo benefício, seja este uma promoção, uma bolsa de pesquisa ou outro tipo de vantagem acadêmica." (OLINTO, 2011, p. 71), principalmente quando são submetidas a processos de avaliação pelos seus pares do sexo masculino. Assim, de acordo com a autora, são "[...] vários os indícios de que, através de diversos mecanismos sutis que se estabelecem no ambiente científico, criam-se vários tipos de barreiras para as mulheres, que dificultam a sua progressão profissional." (OLINTO, 2011, p. 71) e muitos desses mecanismos são tão enraizados nas dinâmicas machistas da sociedade que podem passar despercebidos até pelas próprias mulheres.

Diante desse cenário, o vídeo Nerdologia 125 sobre sexismo nos chamou atenção por se propor a "discutir um pouco sobre desigualdades de gênero", de acordo com descrição do próprio canal, que conta com a apresentação regular de dois homens: o biólogo Atila Iamarino e o historiador Filipe Figueiredo - que também se apresenta como youtuber e podcaster. Figueiredo foi incorporado ao projeto em 2016 para produzir e apresentar vídeos com temática histórica. Toda semana são publicados dois novos vídeos, em terças sobre história e em quintas 
sobre temas variados. Não foi diferente em 17 de março de 2016, data em que foi ao ar o programa sobre sexismo. Mas, ao contrário da tradicional saudação de boas-vindas na voz de um dos apresentadores homens, a narração e o roteiro foram da bióloga Paloma Mieko Sato, que vem a ser também casada com Iamarino - a informação está disponível ao final do vídeo e é fato conhecido pela comunidade que acompanha o canal. Colaboradora regular do Nerdologia, seu nome pode ser encontrado nos créditos de vídeos anteriores e posteriores, principalmente na função de apoio à criação dos roteiros.

\section{Um olhar feminino sobre o sexismo em um ambiente nerd}

No vídeo em questão, Paloma Sato, em narração em off, apresenta dados da Organização Mundial da Saúde (OMS) sobre violência contra as mulheres e compara o cenário brasileiro com países como a China e regiões do Oriente Médio, em que a política do filho único e diretrizes religiosas vêm servindo há décadas para aumentar o quadro de violência contra a mulher. Fala também sobre a participação política das mulheres no Brasil, que, embora possam votar e se candidatar a cargos políticos desde 1933, ainda têm baixa representação parlamentar. Com dados do Fórum Econômico Mundial, ela destaca que a presença feminina no ensino superior do país é de 130 mulheres para cada 100 homens. No entanto, aponta que no Ranking das Diferenças Salariais, o Brasil perde posições porque as mulheres recebem salários menores, além de frequentemente abrirem mão da carreira para se dedicar à família, um reflexo atribuído à falta de ajuda do parceiro em casa e à hegemonia masculina nos cargos mais altos.

Ao tratar do sexismo na ciência, o vídeo do Nerdologia faz um breve comentário, com base em artigo publicado no periódico Proceedings of the National Academy of Sciences (PNAS), sobre como um currículo enviado a laboratórios de pesquisa com nome de um homem recebe mais recomendações e propostas de salário mais altas do que currículos com nomes de mulheres. Cita também Marie Curie e Rosalind Franklin como renomadas cientistas que foram injustiçadas em suas carreiras em função do machismo institucional da academia. Outro aspecto relevante de que trata este vídeo do Nerdologia é a 
relação entre sexismo e cultura nerd, principalmente na representação machista de super-heroínas e na sub-representação de personagens mulheres em jogos, filmes, séries e quadrinhos, produtos midiáticos que compõem esse universo.

Segundo o vídeo, personagens masculinos do universo nerd ficam cada vez mais fortes ao longo dos anos, enquanto personagens femininas são cada vez mais sexualizadas. Decotes e pele exposta tornaram-se um padrão na representação de personagens femininas (desenhadas por homens e para homens) em jogos online, e há estudos, como o de Martey et al. (2014), que apontam que a preferência de jogadores homens por essas personagens seminuas não necessariamente tem relação com a intenção de mascarar seu gênero offline, já que as evidências indicam que eles reforçam noções idealizadas de aparência e comunicação femininas - ou seja, os jogadores homens querem as personagens mulheres como um ideal de sexo oposto a ser controlado.

Ao final do vídeo, Atila Iamarino questiona, em off: "Quem sabe não somos nós, homens, que estamos afastando as mulheres de algo que elas também gostam", ao comentar a generalização de que mulheres não gostam de ciência ou de produtos da cultura nerd. O apresentador ainda orienta que perguntas e queixas sobre o conteúdo do vídeo devem ser direcionadas a ele, em seu perfil no Twitter (@oatila): "E antes de fazê-las, pare para pensar se faria o mesmo se eu tivesse apresentado o episódio, e não a minha esposa”, conclui.

Já apontando questões a serem analisadas atentamente a partir dos comentários deixados nesse vídeo, é impossível não notar, na atitude de Iamarino ao final, um forte marcador de gênero culturalmente associado à posse sobre alguém. Mas não só. Também dá a ver a postura machista de proteção a uma mulher supostamente frágil, além da clara hierarquia sugerida: o canal é comandado por ele e, por pressuposição, tudo que vem dele já está legitimado, o mesmo não valendo para mulheres - cabendo a ele, como marido, receber perguntas e queixas sobre o conteúdo.

Ainda na perspectiva das hierarquias, a ideia de que os homens afastariam as mulheres de algo que elas também gostam, como a cultura nerd, não somente reafirma lugares distintos segundo os gêneros, como simultaneamente naturaliza a divisão e oculta a violência contida em toda 
atitude machista, que seria fator decisivo para que mulheres sintam insegurança diante de ambientes que lhes são hostis. Conforme estudo de Amarasekara e Grant (2018), ao analisar canais de YouTube sobre ciências, foi possível identificar que os poucos canais conduzidos por mulheres tendem a receber mais críticas e comentários hostis do que os apresentados por homens.

Conforme apontado em outros estudos, como o de Megarry (2014), a observação desses espaços indica também uma tensão presente nos debates acadêmicos em torno da internet, principalmente no que se refere à observação da participação online e das questões de gênero que partem da suposição de que a esfera pública online fornece igualdade de manifestações em plataformas sociais democráticas. Estudos como o de Megarry (2014) e este indicam que a questão da igualdade social online é mais ampla e complexa do que o simples fator de paridade numérica alcançado por mulheres e homens nos espaços digitais e, também, em espaços profissionais, como a academia.

A presença de Paloma e as informações por ela apresentadas deflagraram uma série de manifestações no canal e nas redes sociais do Nerdologia, tanto favoráveis quanto contrárias ao tema, à apresentadora e aos argumentos por ela apresentados. No YouTube, foram registrados mais de 15 mil comentários, mais de 98 mil curtidas e cerca de 14 mil descurtidas até a última data de observação, em janeiro de 2019. Além das manifestações registradas nas plataformas do próprio Nerdologia, o vídeo suscitou a gravação de vídeos-respostas de outros usuários do YouTube, com opiniões contrárias e/ou favoráveis aos argumentos apresentados. É a partir das reverberações desse acontecimento que o artigo se aprofunda na análise da problemática do sexismo na divulgação científica, tomando como referência as reações e comentários deixados no canal.

\section{Análise de comentários sobre o vídeo Sexismo | Nerdologia}

Tomamos os comentários como parte constituinte do vídeo e do processo comunicativo por ele desencadeado. Ao privilegiar um olhar para esse ciclo comunicacional, verificamos que os comentários se constituem a partir da mediação do próprio canal, que se apresenta como um espaço em que as explicações têm validade porque se baseiam em argumentos científicos. 
Buscamos identificar não apenas se a temática do sexismo se manteve em debate, mas em que argumentos esse debate se pautou e como os comentários permitem observar diferentes violências simbólicas direcionadas à presença de mulheres na ciência e na divulgação científica.

Como critério metodológico, dentre mais de 15 mil comentários coletados, selecionamos, inicialmente, aqueles que obtiveram maior número de curtidas, ou seja, que foram endossados pelos demais usuários a partir da opção de curtir disponibilizada pela plataforma YouTube. Cabe destacar que foram identificados, no corpus geral, comentários de apoio e reações positivas à participação de Paloma Sato, bem como ao tema do sexismo. No entanto, esses comentários não foram contemplados na análise por não terem figurado dentre aqueles que receberam mais curtidas e respostas da comunidade de comentadores do canal.

A fim de preservar a privacidade dos comentadores, optamos por substituir seus nomes de perfil pelo termo Usuário seguido de um número, que o diferencia dos demais. A apresentação dos comentários na análise não segue uma ordem numérica crescente, uma vez que as falas foram incorporadas em diálogo com as reflexões teórico-metodológicas e podem não corresponder à sequência dos comentários mais curtidos para os menos curtidos. Entretanto, a nomeação dos Usuários em ordem crescente segue essa lógica.

Exceto pelo fato de que alguns nomes dão a ver o possível gênero de quem escreve, a subtração não traz prejuízos à análise. Chama a atenção, no entanto, o fato de os comentários mais curtidos serem, aparentemente, de homens - a partir do que se pode inferir quanto a seus nomes de usuários, fotos e texto que escreveram. Mantivemos a forma original de escrita dos comentários, que embora não tenha consistido em objeto específico de análise, é importante indicador de lógicas de raciocínio e domínio de escrita com coerência, coesão e correção gramatical.

Embora não haja, dentre os comentários selecionados, falas que desqualifiquem a área de formação de Paloma Sato, que é bióloga, assim como Atila Iamarino, o roteiro por ela apresentado é considerado pouco sério por parte dos comentadores, ainda que ela tenha apresentado dados nos mesmos moldes 
de referenciação a artigos e pesquisas, como outros vídeos do canal: "Vou ser sincero, que esperava mais deste nerdologia, eu pensei que o assunto seria tratado com mais seriedade com muito mais ciência [sic]", diz o Usuário 1, que recebeu 989 curtidas. Já na leitura do Usuário 2, que recebeu 859 curtidas, não se trata mais de ciência, mas de apresentar argumentos politicamente corretos: "Nome do canal agora: nerdinhopoliticamentecorreto [sic]". O Usuário 3, com 812 curtidas, diz: "Os decotes são reservados para elas; Claro homem não tem seios, eu vou botar decote a onde? [sic]". E o Usuário 4 comenta: "Atrizes de pornos ganham mais que atores pornôs [sic]", ganhando 802 curtidas da comunidade.

Em outro comentário, pode-se apreender certa ironia na crítica aos dados que Paloma Sato apresenta no vídeo sobre a diferença de salários entre homens e mulheres: "afff mulher narrando fica muito ruim. Coloquem um homem, ahh e não esqueçam de pagar mais a ele! [sic]”, diz o Usuário 5, que recebeu 774 curtidas. Percebe-se também incompreensão quanto ao conceito de sexismo: "Sexismo é fazer um víddeo e focar nos problemas de apenas um sexo [sic]", diz o Usuário 8, que recebeu 610 curtidas. O Usuário 9 faz um comentário na mesma linha, indicando: "Lógica feminina: VIDA REAL: Eu visto o short do tamanho que eu quiser, roupa não indica caráter. VIDEO GAMES: Por que as personagens femininas tem roupas tão curtas? Tá chamando elas de puta, é? WTF? [sic]". Ele recebeu 441 curtidas. A presença de Paloma também é desqualificada e sua voz é considerada chata pelo Usuário 10, que recebe 407 curtidas: "Que mulher de voz chata [sic]", diz.

Coincidentemente, alguns dos comentários que receberam o maior número de curtidas são também aqueles que receberam o maior número de respostas: aqueles escritos pelos usuários 1, 2, 3 e 8. Tais falas provocaram reação de outros, que se engajaram no debate a partir de uma provocação, de uma crítica ou de uma concordância. Não por acaso, esses comentários se caracterizam por desacreditar o conteúdo científico e democrático apresentado no vídeo e podem ser lidos como reações de quem não quer reconhecer ou perder privilégios. Tais comentadores também podem ser identificados como homens, a partir do que se apreende de seus nomes, fotos de perfil e demais 
textualidades dos comentários. Em uma comunidade majoritariamente masculina, cujos integrantes admiram uma cultura nerd também machista e sexista, um vídeo que defende a igualdade de gêneros parece fora da curva, gera decepção e incômodo. Dentre os dez comentários com maior número de curtidas, apenas o Usuário 6 aponta para o fato de que a comunidade que acompanha o Nerdologia parece cultivar uma expectativa de que os argumentos científicos só são válidos quando servem para a ratificação de seus próprios modos de ver o mundo: "Quando a ciência aponta fatos favoráveis a algo que a pessoa não gosta, ou não concorda, ao invés de rever seus conceitos. a pessoa prefere ignorar e descartar os fato [sic]", afirma.

Dentre outros exemplos de comentários deixados no canal, observa-se que a noção de igualdade é distorcida a partir da justificativa de diferenças de idade para aposentadoria e obrigatoriedade do serviço militar para homens, conforme comentário do Usuário 11: "Mulheres se aposentam mais cedo e não são obrigadas anse alistar no exercito, querem igualdade ou não.? [sic]”. Neste mesmo sentido, destacamos também o comentário do Usuário 12:

Acho que a resposta já foi dada ! são coisas feita por homens para homens! Sou do tempo que quem trocava uma festa do colegial, por jogar mario kart com amigos era rejeitado pelas mulheres. Mulheres sempre tratou mal nos homens nerds e querem ser bem aceita no mundo que nos criamos ? para simplificar! A mulherada pegou o bonde andando e já que senta na janela espera um tempo que tudo vai fica bem, uma hora ou outra vcs serão aceitas. Dica pra não sofre bullying1:Se ta num grupo nerd certifique-se de fala de nerdices e não de si mesma.2:Em jogos online certifique-se de não fala sobre ter pepeca ou pipi. Não seja Attwhore. [sic]

O termo "attwhore" é a abreviação do conceito, em inglês, attention whore (puta da atenção ou vadia da atenção, em tradução livre). A expressão é usada para se referir a quem faz de tudo em troca de atenção na Internet e é mais comumente atribuída a mulheres. A própria origem etimológica do termo (sendo whore uma palavra associada a xingamentos e desqualificações de mulheres) já indica que seu uso parte de uma crítica misógina a um comportamento que, aos olhos de outros usuários (usualmente, homens), é interpretado como mero desejo de atenção, seja a partir do uso de atributos sexuais ou de reafirmação de 
gostos pessoais relacionados a universos mais associados a homens, como jogos eletrônicos e a própria cultura nerd.

O Usuário 13, que recebeu 113 respostas em sua publicação, traz à tona questões relacionadas aos papéis desempenhados por pais e mães, a divisão do trabalho doméstico e estereótipos de gênero que merecem ser melhor contextualizados, uma vez que o Usuário se utiliza parcialmente de argumentos expostos no vídeo para reverter a situação a favor dos homens, colocando o pensamento feminista como um discurso opressor, que segregaria homens e beneficiaria mulheres:

Realmente existe muito "Machismo", mas na hora da disputa de guarda as "Feministas"; não abrem mão da preferencia das crianças ficarem com as mães, se as crianças ficam com os pais as "Feministas"; não precisam pagar pensão, não são obrigadas a se alistar ao exercito, quando vemos vídeos de homem sendo agredido por mulheres você da risadas da situação (não acho qualquer tipo de violência engraçada), a maioria das pessoas que vivem nas ruas são homens, homens geralmente são os que fazem a maioria dos trabalhos perigosos.... ahhh e sobre os personagens em jogos de MMORPG (os que deram aquelas respostas escrotas são noobs) geralmente os personagens femininos são mais fortes e os de jogos FPS os personagens femininos geralmente são mais ágeis e mais difíceis de acertar os tiros. [sic]

Este tipo de comentário pode ser associado ao que Megarry (2014) identificou como silenciamento de vozes femininas e assédio sexual online, ao estudar a hashtag \#mencallmethings na rede social Twitter. A autora aponta que a presença de mulheres em espaços públicos transgride a estabilidade da divisão público/privado nas sociedades patriarcais e que, ao serem excluídas da participação online por meio do assédio com base em seu sexo, as mulheres passam a ter que lidar com o policiamento de suas vozes também nesses ambientes supostamente mais democráticos. Megarry (2014) defende, então, que o assédio online de mulheres é mais adequadamente conceituado como assédio sexual online quando se reconhece o propósito político do comportamento de assédio masculino: o silenciamento de mulheres que ousam falar na esfera pública online (MEGARRY, 2014).

Além da seleção de comentários mais curtidos e mais respondidos, outras associações que podem ser identificadas dentre os milhares de registros coletados podem ser divididas, basicamente, em três categorias: 
a) Manifestações de apoio ao vídeo e à presença de Paloma;

b) Manifestações contrárias, que criticam ou menosprezam sua presença pelo fato de ser mulher;

c) Manifestações que buscam desqualificar as informações apresentadas, com a justificativa de que não são científicas e que, por isso, depõem contra a proposta do canal.

A seguir, deteremo-nos brevemente à análise de comentários que se encaixam na terceira categoria, por considerarmos que eles dão a ver um aspecto mais amplo da legitimação da ciência e dos sujeitos considerados aptos a produzirem conhecimento científico e falarem sobre ciência. Tais mensagens foram identificadas aleatoriamente dentre as mais de 15 mil mensagens coletadas por contribuírem com a compreensão de como o sexismo compõe o ciclo comunicacional do canal Nerdologia, em especial no vídeo sobre o tema.

O Usuário 17 escreve: "Nerdologia....para de falar dessas viadagem e voltem a falar de assuntos científicos e nerds [sic]". Já o Usuário 18 afirma: "O video mais idiota do Nerdologia até hoje. Deve ser porque tem uma mulher apresentando [sic]". O Usuário 19 é mais enfático em seu comentário sobre o vídeo:

sexismo??? agora nerdologia viro canal feminista ate agora ja vi 163 deslike sinal que nessa sua abordagem feminista ninguen andou gostando desse video. fracasso de video nerdologia. Aff tanta abobrinha. decepicionado o pior video do nerdologia. Nada de interessante. afff afff afff quui bosta de video peerdi meu tempo [sic].

Exemplos de comentários como os descritos existem às centenas na coleta realizada para a redação deste artigo e contribuem para uma reflexão sobre o lugar das mulheres na ciência e na divulgação científica, a partir de uma problemática narrativa, sobre a autoridade de quem pode falar de ciência. Esse movimento se dá a partir das possibilidades que as narrativas oferecem ao problematizar a legitimação e a credibilidade das mulheres, conforme veremos a seguir. 


\title{
5 A questão da legitimação: quem pode falar de ciência?
}

A partir do pensamento de Jean-François Lyotard (2002), podemos afirmar que as questões emergentes da análise dos comentários deixados no vídeo sobre sexismo do canal Nerdologia têm relação com a solução dada à legitimação das novas autoridades quando, a partir do século XX, a ciência enfrentou mudanças referentes à sociedade da informação. Ao final da década de 1970, Lyotard (2002) já discutia a questão da legitimação como central às discussões sobre o fazer científico:

\begin{abstract}
A questão da legitimação encontra-se, desde Platão, indissoluvelmente associada à legitimação do legislador. Nesta perspectiva, o direito de decidir sobre o que é verdadeiro não é independente do direito de decidir sobre o que é justo, mesmo se os enunciados submetidos respectivamente a esta e àquela autoridade forem de natureza diferente. (LYOTARD, 2002, p. 13).
\end{abstract}

Ainda sobre a legitimação e as regras do jogo da ciência, o autor apresenta a dificuldade de se legislar sobre a prova e como a figura do cientista como expert, autoridade, assume o papel antes ocupado pela busca metafísica de uma prova primeira ou de uma autoridade transcendente:

[...] reconhece-se que as condições do verdadeiro, isto é, as regras de jogo da ciência, são imanentes a este jogo, que elas não podem ser estabelecidas de outro modo a não ser no seio de um debate já ele mesmo científico, e que não existe outra prova de que as regras sejam boas, senão o fato delas formarem o consenso dos experts. (LYOTARD, 2002, p. 54).

Com relação à autoridade da ciência, identifica-se, em comentários como o do Usuário 20, a necessidade de questionar a origem dos dados, as fontes consultadas para que se possa checar as informações fornecidas no vídeo:

de onde saio os dados que acada 15 seg uma mulher e espancada ou que no brasil as mulheres ganham menos nos mesmo cargos (mesma empresas tambem)? nao encontrei [sic].

O Usuário 21, em uma mesma lógica de confrontação à legitimidade das informações trazidas por Paloma, equivale os dados informados no vídeo a uma mera opinião da apresentadora: "A primeira metade do vídeo foi sensacional, a segunda metade foi bem menos embasada em fatos e sim em opiniões [...][sic]". O Usuário 22 faz um comentário que parece querer traçar uma linha entre o que 
é considerado científico (e, por isso, deveria ser abordado pelo canal) e outros assuntos que, por estarem fora das competências da ciência, não deveriam ser pauta do Nerdologia:

Entendi a iniciativa, e acho valida, mas sinceramente acho q esse não é um assunto para o nerdologia, é um assunto q tem muito mais a ver com opinião politica e social do q com ciência. Aliás acho q não tem nada a ver com ciência [sic].

Comentários como esse tratam de aspectos da legitimação do próprio campo científico e do que pode ou não ser chamado de "ciência", principalmente quando consideramos que a revolução na ciência, ocorrida nos séculos XVII e XVIII, foi responsável pelo estatuto da "ciência masculina", pública e racional, em oposição à atividade feminina, da vida privada, doméstica:

A ciência fazia parte do território que cabia à parte masculina, nessa reestruturação da cultura no século XVIII. Porque a ciência, como qualquer outra profissão, habita o domínio público em que as mulheres (ou a feminilidade) não ousavam agir, a ciência veio a ser vista como decididamente masculina. (SCHIEBINGER, 2001, p. 142).

Keller (1985) aponta que, em uma perspectiva feminista, a questão mais imediata que se coloca para as ciências, principalmente as ciências "naturais", é como certa mitologia popular profundamente arraigada ao imaginário social contribui para moldar a objetividade, a razão e a mente como masculinas, e a subjetividade, o sentimento e a natureza como femininos:

Nesta divisão do trabalho emocional e intelectual, as mulheres têm sido as responsáveis protetoras do pessoal, do emocional, do particular, ao passo que a Ciência - por excelência, o domínio do impessoal, do racional e do geral - tem sido a reserva dos homens. (KELLER, 1985, p. 7, tradução nossa ${ }^{1}$ ).

Para a autora, a consequência de tal divisão não é a simples exclusão das mulheres das ciências, embora isso também aconteça, principalmente nas áreas consideradas metaforicamente mais "duras", como a Física e as Engenharias, mas sintoma de um abismo mais amplo e profundo entre feminino e masculino, subjetivo e objetivo, que afeta toda a sociedade, mulheres ou homens. Do mesmo modo, para Schiebinger (2001, p. 150), a visão profissional do cientista 
como um homem branco de jaleco "[...] repousa sobre uma divisão de trabalho não explicitada.". Para a autora, esse complexo de imagens masculinas dominantes contribui para criar barreiras simbólicas para a presença das mulheres nas ciências (SCHIEBINGER, 2001).

Por isso, o fenômeno desencadeado pela apresentação do vídeo feito por Paloma Sato também remonta, ainda que indiretamente, à questão da divisão sexual do trabalho. Problemáticas como essa dão a ver ainda o longo caminho a ser percorrido por quem se propõe a pensar e militar em prol da presença das mulheres e em defesa da igualdade de gêneros no ambiente da produção acadêmico-científica. Outro fator que não deve ser ignorado no caso em questão é que, conforme relembra Schiebinger (2001):

Mulheres trabalhando com homens, e especialmente com seus maridos, têm sido tradicionalmente consideradas parceiras menos importantes. Supõe-se, geralmente, que Pierre Curie foi principalmente responsável pelo Prêmio Nobel que compartilhou com sua esposa, Marie, mas de fato ela participou igualmente no trabalho. Foi dito que Enrico Fermi "deu" à sua colega Maria Goeppert Mayer o modelo para o Prêmio Nobel que ela recebeu em física. (SCHIEBINGER, 2001, p. 101).

Esse recorte não pode ser ignorado diante da força da figura de Atila Iamarino na comunidade de divulgadores científicos no Brasil que se utilizam de canais de amplo acesso na internet, e da invisibilidade de Paloma Sato nesse processo. Depois do vídeo analisado, ela não se fez presente em nenhum outro vídeo apresentado no canal, embora continue sendo creditada como equipe de apoio em vídeos subsequentes.

No escopo das ações de comunicação da ciência, buscamos também refletir sobre o que significa falar de sexismo em um projeto de divulgação científica cujo público é, majoritariamente, formado por homens jovens. Em entrevista (COSTA, 2017), Iamarino afirmou que esperava que o canal tivesse um público mais feminino, mas que a audiência é composta, majoritariamente, por homens entre 18 e 33 anos. Ainda que não seja tema constante ou central das publicações do Nerdologia, as questões de gênero perpassam diversos temas e discussões promovidas pelo projeto. O apresentador afirmou na entrevista: 
Eu acho muito triste, não é uma realidade que eu quero nem cogitar, pensar que eu teria que tratar de temas femininos para atrair o público feminino. Não me vejo tratando de temas masculinos. Eu não tô falando ali de futebol. Nem futebol, não tô falando ali de barba, para só falar com homens. Eu não vejo porque eu deveria falar de maquiagem e esmalte para falar com mulheres. Mas talvez seja uma coisa necessária para atrair um público feminino maior. (IAMARINO apud COSTA, 2017)

Assim como notamos na fala de Atila Iamarino ao final do vídeo apresentado por Paloma Mieko Sato, esse trecho da entrevista concedida pelo youtuber deixa transparecer associações sobredeterminadas por todos os estereótipos e preconceitos de gênero, aqui explicitados pelos mundos do futebol, para os homens, e da maquiagem, para as mulheres.

Essas associações são exemplos desta tensa relação que se materializa em estereótipos cotidianos e na persistente crença de que nem todas as ciências pertencem às mulheres (elas são mais de humanas e sociais do que de exatas e da terra?), sobre suas habilidades cognitivas (existem diferenças entre cérebros de homens e mulheres?), sobre suas capacidades de liderança em ambientes ditos masculinos, dentre outras. Tais estereótipos estão relacionados ao que Keller já apontava, em 1985, sobre a desigualdade de gêneros nas ciências, ao indicar que o fato de a população científica ser predominantemente masculina é, em si, uma consequência e não uma causa da atribuição da masculinidade ao pensamento científico. Diante desse quadro, segundo ela:

O que requer discussão é uma crença e não uma realidade, embora as formas pelas quais a realidade é moldada por nossas crenças sejam múltiplas e também precisem ser articuladas. (KELLER, 1985 , p. 76-77, tradução nossa) ${ }^{2}$.

\section{Mulheres na divulgação científica: lugar de vulnerabilidade?}

O pensamento de Judith Butler (2014) surge a nós nas considerações finais como uma resposta propositiva ao cenário previamente analisado. Ao argumentar que a vulnerabilidade, entendida como uma exposição deliberada ao poder, faz parte do próprio significado da resistência política, Butler (2014) nos permite afirmar que, diante da desigualdade de gênero na ciência e na divulgação científica, a presença das mulheres nesses espaços torna-se também uma ação política empoderadora, que deixa à mostra a vulnerabilidade 
decorrente do sexismo, da misoginia, da defesa de privilégios para os homens e das hierarquizações e violências físicas e simbólicas deles decorrentes.

Conforme explicita a autora, isso não se dá como uma condição de existência vulnerável em si, mas como uma condição temporária em que as ideias de resistência e vulnerabilidade tensionam os arranjos sociais previamente estabelecidos. Pensar a vulnerabilidade como resistência é potente nesse caso do Nerdologia sobre sexismo, porque entendemos que é justamente a exposição da bióloga Paloma Mieko Sato, pesquisadora, casada com um dos apresentadores principais do canal, perante um público majoritariamente masculino, em um campo dominado por homens, que faz um movimento de resistência importante.

A presença de Paloma contribui para derrubar o binarismo, o que, para Butler (2014), é uma tarefa feminista. Diante da pergunta de por que se deveria discutir gênero na divulgação científica, a superação de uma visão da ciência masculina nos parece também ser uma importante missão política das ações de comunicação pública da ciência. Associar um determinado aspecto do fazer científico ou da divulgação científica ao masculino ou ao feminino significa um afastamento de uma posição neutra em relação à Ciência, sem cair no relativismo absoluto, buscando apontar os endereçamentos subjetivos que se materializam textualmente em conteúdos de divulgação científica e em suas reverberações, ainda que esses se pretendam objetivos e respaldados pelo método e pela institucionalização da definição do que é científico.

Nesse sentido, estudos no campo da arqueologia têm demonstrado o quanto interpretações sobre contribuições de homens e mulheres para a história da humanidade são frequentemente marcadas pelo gênero de quem conduz as pesquisas. Essas indicações estão em Londa Schiebinger (2001), já referida neste artigo, mas também as encontramos no livro O sexo invisível: destapando o verdadeiro papel das mulheres na pré-história, de Adovasio, Soffer e Page (2008), obra que defende a tese de que, da interpretação de pinturas nas cavernas aos achados de corpos mais ou menos preservados, de ossos e utensílios identificados como de uso cotidiano ou ritualístico, a leitura dos significados e a marcação do "sexo" a que pertenceriam os artefatos e restos humanos têm sido, não raro, contaminado pela cultura machista dos nossos tempos, atribuindo a 
nossos antepassados divisões de gênero que provavelmente não correspondem ao efetivamente vivido por aquelas pessoas. Mas, sobretudo, ocultando o fato de mulheres terem participado, em diversos momentos e culturas pré-históricas, tanto quanto os homens, dos avanços que permitiram colonizar a terra.

Os autores destacam, por exemplo, que a agricultura, com elevado grau de certeza, foi uma contribuição das mulheres para a humanidade, marcando importante virada do estilo de vida nômade para o sedentário, mas, contraditoriamente, instaurando as condições ideais para a constituição das primeiras divisões sociais fundadas no sexismo.

Com a invenção das mulheres, não só o seu estatuto mas a miríade de papéis e actividades que desempenhavam começaram por fim a tornar-se visíveis para nós hoje; e essa visibilidade aumenta à medida que atingimos eras mais recentes. Também já podemos considerar que as origens da agricultura acarretam não apenas as vantagens de uma vida sedentária, mas também - o que é uma ironia - em muitos casos, a erosão da igualdade de géneros. (ADOVASIO, SOFFER; PAGE, 2008, p. 236)

Retomando a perspectiva dos comentários de usuários da internet sob a ótica dos efeitos desagradáveis e hostis, é relevante notar que a repercussão negativa, majoritariamente entre homens, do vídeo feito por Paloma Sato não deve ser entendida somente a partir das hierarquias de gênero que imperam na sociedade brasileira de forma a atingir praticamente todas as esferas das relações sociais. Elas são indicativas de intolerâncias, da recusa à aceitação de diferenças e de estratégias de manutenção de privilégios.

No que diz respeito mais especificamente ao universo da ciência e dos seus processos de comunicação e publicização, o desrespeito, os preconceitos e os estereótipos desqualificadores são indícios de modos de configuração do fazer e divulgar ciência marcado por clivagens, desigualdades e hierarquizações que são ainda mais complexos quando pensados segundo as lógicas da interseccionalidade, se entram em cena, além do sexismo, variáveis como racismo, homofobia e outras determinantes. Eis uma seara de investigação que se encontra em aberto.

Se não podemos nos livrar das influências culturais que ainda insistem em determinar os locais e os debates públicos para os homens, destinando às 
mulheres as questões privadas, da família e do lar, é pelo desenvolvimento de uma consciência crítica de como o gênero influencia a ciência que nos permitiremos "[...] organizar a ciência de acordo com valores preferenciais, ao invés de negligentes." (SCHIEBINGER, 2001, p. 274). Tal consciência deve passar a fazer parte de projetos de pesquisa para que nossa capacidade de compreender a pesquisa supere os binarismos, o sexismo e o machismo (muitas vezes velados) da academia. E, assim, contribua para uma ciência mais diversa, bem como para a diversidade de gêneros nos processos de comunicação pública da ciência, seja por meio de revistas especializadas, seja por meio de canais populares na internet, como o Nerdologia.

\section{Agradecimentos}

Este artigo resulta, em parte, de pesquisas financiadas pelo Conselho Nacional de Desenvolvimento Científico e Tecnológico (CNPq) e pela Fundação de Amparo à Pesquisa do Estado de Minas Gerais (Fapemig).

\section{Referências}

ADOVASIO, James M.; SOFFER, Olga; PAGE, Jake. O sexo invisível: destapando o verdadeiro papel das mulheres na pré-história. Mem Martins: Europa-América, 2008.

ANDERSON, Ashley A. et al. The 'Nasty Effect': Online Incivility and Risk Perceptions of Emerging Technologies. Journal of Computer-Mediated Communication, Pennsylvania, v. 1, n. 19, p. 373-387, 2014.

AMARASEKARA, Inoka e GRANT, Will J. Exploring the YouTube science communication gender gap: A sentiment analysis. Public Understanding of Science, [s.1.] v. 28, n. 1, p. 68-84, 2019. Disponível em: https://doi.org/10.1177/0963662518786654. Acesso em: 20 out. 2019.

BILEFSKY, Dan. Women respond to Nobel Laureate's 'Trouble with girls'. In: The New York Times. Londres, 11 jun. 2015. Disponível em: https://www.nytimes.com/2015/06/12/world/europe/tim-hunt-nobel-laureateresigns-sexist-women-female-scientists.html. Acesso em: out. 2019.

BUTLER, Judith. Rethinking vulnerability and resistance. In: BUTLER, Judith; GAMBETTI, Zeynep; SABSAY, Leticia. Vulnerability in resistance. Madrid: Duke University Press, p.12-27, 2014. 
ELSEVIER. Gender in the global research landscape: Analysis of research performance through a gender lens across 20 years, 12 geographies, and 27 subject areas. Elsevier Research Intelligence, [s.1.], 2017.

COSTA, Verônica Soares da. "Trato, principalmente, da ciência que sou". Aspectos não-científicos em projetos de divulgação da ciência: entretenimento, cultura nerd e o perfil de público do Nerdologia. Entrevista com o pesquisador Atila Iamarino, criador do canal Nerdologia, no YouTube. In: Revista Científica de Comunicação Social do Centro Universitário de Belo Horizonte (UniBH) e-Com, Belo Horizonte, v. 10, n. 2, p. 72-83, 2017.

KELLER, Evelyn Fox. Reflections on Gender and Science. New Haven: Yale University Press, 1985.

KENDALL, Lori. Nerd nation: Images of nerds in US popular culture. International Journal of Cultural Studies, Londres, v. 2, n. 2, p. 206-283, 1999.

KENDALL, Lori. "Oh no! I'm a nerd!": Hegemonic masculinity on an online forum. Gender \& Society, Londres, v. 14, n. 2, p. 256-274, 2000.

KENDALL, Lori. White and Nerdy: Computers, Race, and the Nerd Stereotype. The Journal of Popular Culture, New Jersey, v. 44, n. 3, p. 256-274, 2011.

KNOW YOUR MEME. Significado de 'attention whore'. Disponível em https://knowyourmeme.com/memes/attention-whore. Acesso em: out. 2019.

LYOTARD, Jean-François. A condição pós-moderna. $7^{\text {a }}$ ed. Rio de Janeiro: José Olympio, 2002.

MARTEY, Rosa Mikeal et al. The strategic female: gender-switching and player behavior in online games. Information, Communication \& Society, [s.l.], v. 17, n. 3, p. 286-300, 2014.

MEGARRY, Jessica. Online incivility or sexual harassment? Conceptualising women's experiences in the digital age. Women's Studies International Forum, [s.1.], v. 47, n. 1, p. 46-55, 2014.

MIEKO, Paloma. Nerdologia Sexismo. 2016. (7min 46s). Disponível em: https://youtu.be/cpnJ4psOoZc. Acesso em: 18 jan. 2019.

OLINTO, Gilda. A inclusão das mulheres nas carreiras de ciência e tecnologia no Brasil. Inclusão Social, Brasília, v. 5, n. 1, p. 68-77, 2011.

REZNIK, Gabriela. et al. Como adolescentes apreendem a ciência e a profissão de cientista? Estudos Feministas, Florianópolis, v. 25, n. 2, p. 829-855, 2017. 
SCHIEBINGER, Londa. O feminismo mudou a ciência? Bauru: EDUSC, 2001.

SOCIALBLADE. Top 250 YouTubers Tech Channels. Disponível em: https://socialblade.com/youtube/top/category/tech/mostsubscribed. Acesso em: 20 out. 2019.

\title{
Can't women talk about science? Analysis of sexist comments in Nerdologia YouTube channel
}

\begin{abstract}
The article focuses on sexism approaches in science communication based on the analysis of comments that received the highest number of likes and answers - among more than 15.000 comments identified - in a YouTube video by Nerdologia about sexism. The study indicates a predominance of negative repercussion on the narrative conducted by a woman in an environment originally occupied by male presenters. The purpose of the article is to reveal textual senses to users' reactions as part of YouTube's communication cycle, considering likes and responses as aspects that validate sexist comments that delegitimize the female presence and distort arguments on gender equality. The analysis also points to ways in which women find themselves in a position of vulnerability as science communicators, considering prejudices, stereotypes and disqualification as components of socio-cultural, economic, and political processes that weaken the performance of women in institutions that hold statuses of privilege - such as Science. Disqualifying stereotypes about women indicate how science and science communication have cleavages, inequalities and hierarchies in gender relations, and also indicate the need to develop a critical awareness on how gender stereotypes influence science and science communication
\end{abstract}

Keywords: Sexism. Science Communication. YouTube. Comments. Vulnerability.

Recebido: 02/02/2019

Aceito: 10/05/2019

\footnotetext{
${ }^{1}$ No original: "In this division of emotional and intellectual labor, women have been the guarantors and protectors of the personal, the emotional, the particular, whereas science the province par excellence of the impersonal, the rational, and the general has been the preserve of men."

${ }^{2}$ No original: "What requires discussion is a belief rather than a reality, although the ways in which reality is shaped by our beliefs are manifold and also need articulating.".
} 